\title{
OPTIMALISASI PEMETAAN FASE PERTUMBUHAN PADI BERDASARKAN ANALISA POLA REFLEKTAN DENGAN DATA HIPERSPEKTRAL Studi Kasus : Kabupaten Karawang
}

\author{
M. A. Rauf Syafriyyin, Bangun Mulyo Sukojo \\ Jurusan Teknik Geomatika, Fakultas Teknik Sipil dan Perencanaan, Institut Teknologi Sepuluh Nopember (ITS) \\ Jl. Arief Rahman Hakim, Surabaya 60111 \\ e-mail: bangunms@gmail.com
}

\begin{abstract}
Abstrak
Kebutuhan akan beras sebagai sumber makanan pokok yang dikonsumsi oleh lebih dari $90 \%$ masyarakat Indonesia menjadikan padi sebagai komoditas strategis yang berperan penting dalam ketahanan pangan nasional. Untuk memenuhi kebutuhan tersebut diperlukan teknologi yang tepat guna dalam memetakan fase pertumbuhan padi sebagai alat untuk memonitor dan mengevaluasi pertumbuhan padi. Teknologi hiperspektral yang memiliki ratusan kanal mampu menyajikan spektral yang kontinu pada setiap objek yang diamati sehingga melalui data hiperspektral perbedaan fase pertumbuhan dapat lebih mudah diamati melalui analisis pola dan karakteristik nilai reflektan spektral yang kemudian diklasifikasikan kedalam fase pertumbuhan padi. Pemetaan fase pertumbuhan padi dilakukan pada citra HyMap dengan metode klasifikasi Spectral Angle Mapper (SAM) dan Support Vector Machine (SVM) yang merupakan metode klasifikasi terbimbing (supervised) yang digunakan untuk mengenali pola nilai spektral dari suatu objek berdasarkan informasi dari piksel citra. Dari hasil pemetaan fase pertumbuhan padi yang dibagi menjadi 9 kelas mewakili setiap stage tumbuh padi yaitu (Seedling, Tillering, Stem Elongation, Penicle Initation to booting, Heading, Flowering, Milk Grain, Dough Grain, dan Mature Grain) diperoleh ketelitian SAM sebesar 82,609 \% dan SVM sebesar $54,348 \%$. Hal ini menunjukkan pemetaan fase pertumbuhan padi dengan metode analisis pola reflektan spektral dengan metode SAM memiliki hasil yang lebih akurat dan signifikan daripada metode SVM.
\end{abstract}

Kata kunci- Padi, HyMap, Nilai Spektral, SAM, SVM

\section{PENDAHULUAN}

Padi adalah tanaman pangan penghasil beras yang banyak dibudidayakan oleh petani Indonesia karena 90 \% masyarakat Indonesia mengkonsumsi beras sebagai sumber makanan pokok. Hal tersebut menjadikan tanaman padi sebagai komoditas strategis yang berperan penting dalam perekonomian dan ketahanan pangan nasional [1]. Seiring meningkatnya konsumsi masyarakat akan beras, diperlukan teknologi yang tepat guna dalam mengestimasi produktivitas padi untuk mendukung tercukupinya ketersediaan pangan nasional.

Teknologi hiperspektral penginderaan jauh merupakan pengembangan dari teknologi multispektral, yang memiliki ratusan kanal yang sempit sehingga mampu menyajikan spektral yang kontinu pada setiap objek yang diamati. Dengan memiliki ratusan bahkan ribuan kanal yang sempit, data hiperspektral mampu menyajikan informasi jauh lebih detil daripada data kanal lebar dalam menghitung variabel- variabel biofisik dan kimia dari tanaman [2]. Dari data hiperspektral tersebut kita dapat memperoleh informasi yang akurat mengenai kondisi tanaman pada suatu area yang dapat lebih detil dibedakan seperti pengamatan fase pertumbuhan tanaman, parameter biofisik tanaman seperti indeks luas daun (Leaf Area Indeks), kandungan klorofil tanaman dan lain-lain [3]. Melalui data hiperspektral perbedaan fase pertumbuhan suatu vegetasi dapat lebih mudah diamati melalui analisis nilai spektral yang kemudian diklasifikasikan kedalam fase pertumbuhan.

Pada proses pengolahan citra hiperspektral metode klasifikasi Spectral Angle Mapper (SAM) dan Support Vector Machine (SVM) merupakan metode klasifikasi terbimbing (supervised) yang digunakan untuk mengenali pola nilai spektral dari suatu objek berdasarkan informasi dari piksel citra. Dalam penelitian ini akan dikaji tentang metode klasifikasi dengan analisa nilai reflektan spektral dalam memetakan fase pertumbuhan padi dengan data hiperspektral 
citra HyMap. Kajian ini diharapkan dapat memperoleh hasil yang akurat dan signifikan dalam pemetaan fase pertumbuhan padi yang kemudian digunakan untuk menganalisa dan mengevaluasi pertumbuhan padi.

\section{METODOLOGI PENELITIAN}

Penelitian ini area studi yang digunakan adalah wilayah Kabupaten Karawang, Jawa Barat

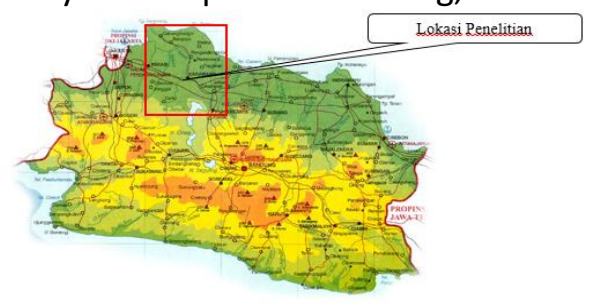

Gambar 1. Lokasi penelitian (sumber: http://maps.google.co.id)

Data yang digunakan dalam penelitian ini antara lain adalah citra HyMap Kabupaten Karawang, Data reflektan in situ padi dan data Parameter Biofisik padi (LAl dan plant height). Pada penelitian ini proses pengolahan data dapat digambarkan seperti diagram alir berikut :

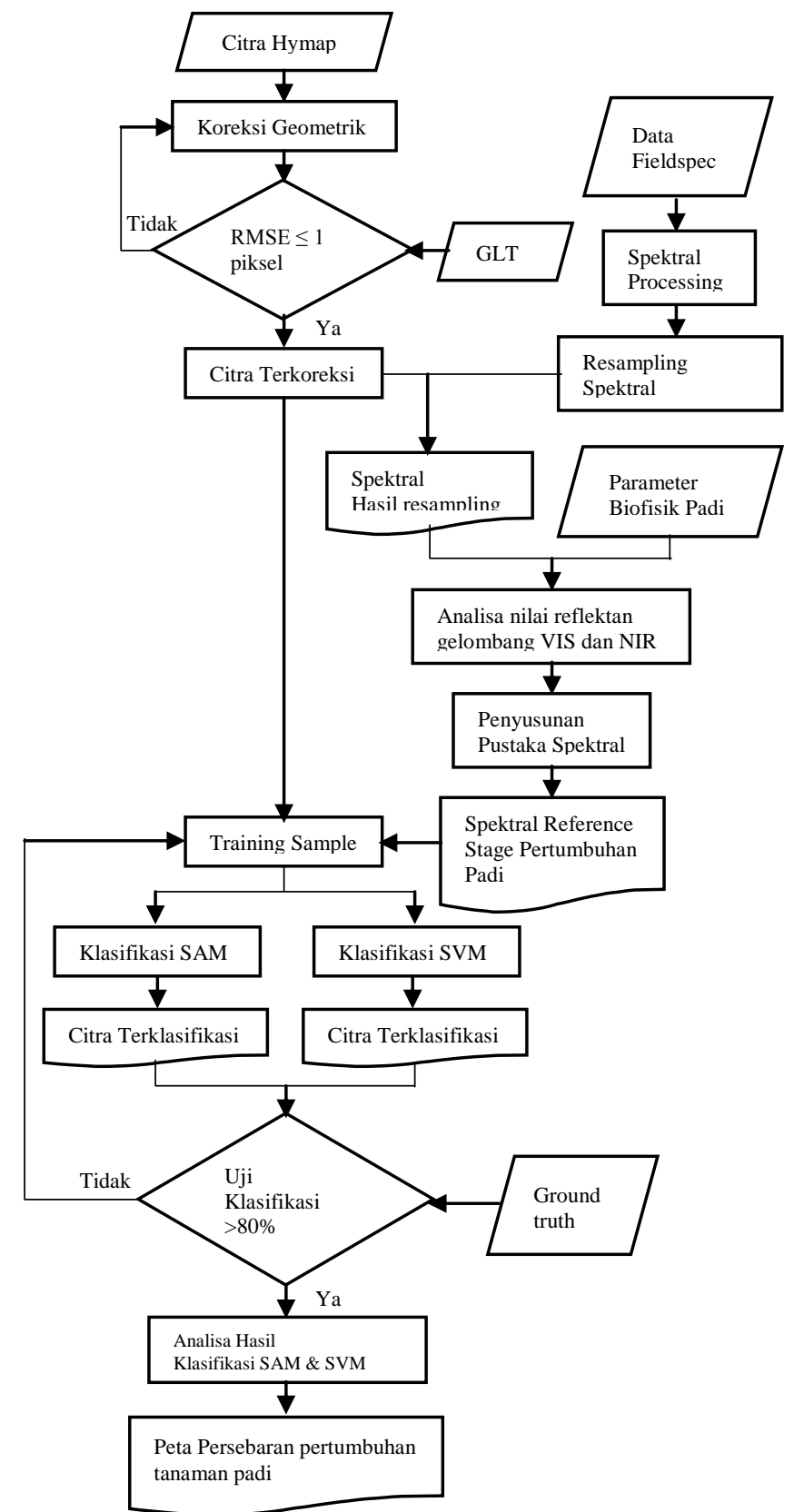

Gambar 2. Diagram Alir Pengolahan Data

Berdasarkan diagram alir diatas, secara umum penelitian ini dibagi menjadi tahapan sebagai berikut :

Pengolahan citra HyMap yang meliputi proses koreksi kesalahan geometrik pada 10 layer citra HyMap wilayah Kabupaten Karawang.

Penyusunan pustaka spektral untuk mendapatkan spectral reference fase pertumbuhan padi berdasarkan analisa hubungan parameter biofisik dengan nilai reflektan in situ padi pada panjang gelombang visible (VIS) dan near infrared (NIR). 
Klasifikasi citra HyMap berdasarkan spectral reference yang telah disusun dengan metode SAM dan SVM kemudian dilakukan analisa hasil klasifikasi SAM dan SVM dengan menguji hasil ketelitian.

SAM mengklasifikasikan spektral citra menggunakan sudut $n-D$ dalam mencocokkan piksel dengan spektra referensi. Algoritma ini menentukan kesamaan antra 2 spektra dengan menghitung sudut antara kedua nilai spektra dan menjadikannya sebagai vektor arah dalam jumlah dimensi yang sama dengan jumlah kanal.

SVM mengklasifikasikan piksel citra dengan mencari hyperplane terbaik yang berfungsi sebagai pemisah dua buah kelas pada input space berdasarkan nilai pola distribusi statistik dalam fitur region kelas sebagai input pada proses klasifikasi.

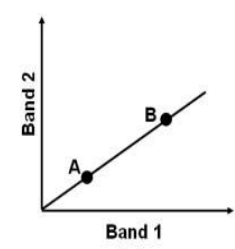

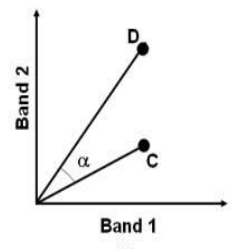

(b)

Gambar 3. Konsep SAM

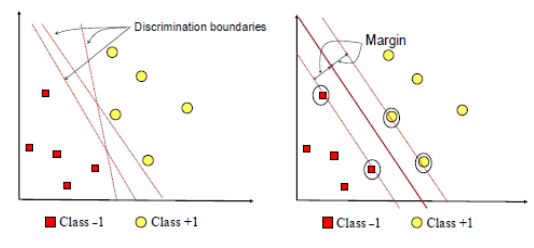

(a) Gambar 4. Konsep SVM

\section{HASIL DAN PEMBAHASAN}

\section{Hasil Koreksi Geometrik Citra HyMap}

Koreksi geometrik dilakukan pada setiap lajur dari citra HyMap dengan menggunakan Geometric Lookup Table (GLT) yaitu sebuah metode pengkoreksian pada setiap piksel untuk penentuan posisi geospasial dari lintang dan bujur pada suatu area.

Dari proses koreksi geometrik pada setiap lajur didapatkan nilai RMS Error kurang dari 1 pixel sebagai berikut :
Tabel 1. RMS Error tiap lajur

\begin{tabular}{|l|l|}
\hline No. Lajur & RMS Error \\
\hline 1 & 0.455 \\
\hline 2 & 0.148 \\
\hline 3 & 0.061 \\
\hline 4 & 0.134 \\
\hline 5 & 0.143 \\
\hline 6 & 0.086 \\
\hline 7 & 0.028 \\
\hline 8 & 0.307 \\
\hline 9 & 0.203 \\
\hline 10 & 0.112 \\
\hline
\end{tabular}

Analisa Nilai Reflektan Pertumbuhan Padi

Data reflektan fieldspec pada setiap quadrat area yang telah dilakukan proses resampling spektral memiliki resolusi spektral yang sama dengan sensor HyMap. Nilai Reflektan in situ padi yang telah dibagi setiap fase pertumbuhan padi (vegetatif, reproduktif dan ripening) dilakukan analisa nilai reflektan spektral pada spektrum gelombang visible dan near infrared.

Pada spektrum gelombang visible terletak pada panjang gelombang $0.4-0.7 \mu \mathrm{m}$ yang memiliki respon terhadap warna yang tampak oleh mata yaitu pada warna biru $(0,455-0,492 \mu \mathrm{m})$, hijau $(0,492-0,588 \mu \mathrm{m})$ dan merah $(0,622-0,780$ $\mu \mathrm{m})$ Sedangkan pada spektrum panjang gelombang near infrared pada panjang gelombang $0.7-1.3 \mu \mathrm{m}$ menjelaskan struktur morfologi daun dari vegetasi [4]. Dengan menganalisa nilai reflektan pada panjang gelombang visible dan near infrared maka kondisi vegetasi dapat diamati berdasarkan warna dan struktur morfologi daunnya. Struktur daun pada vegetasi dapat diketahui melalui parameter biofisik LAI.

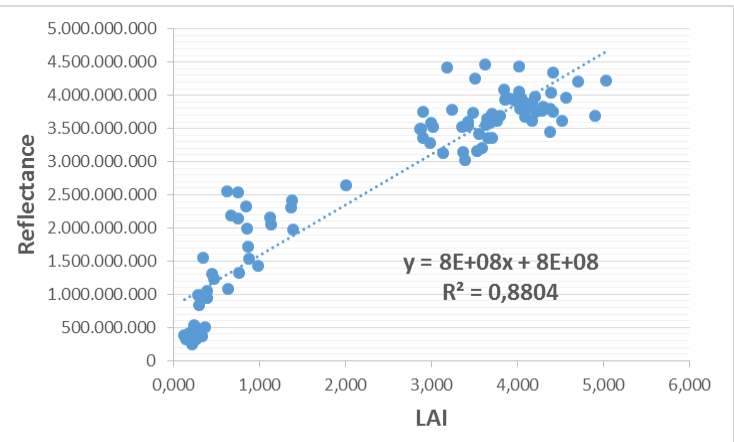

Gambar 5. Korelasi nilai LAI dan nilai reflaktan panjang gelombang near infrared 
Pada gambar 3 ditunjukkan bahwa LAI memiliki hubungan yang kuat terhadap nilai reflektan pada panjang gelombang near infrared ditunjukkan dengan nilai koefisien determinasi yang tinggi $R^{2}=0,8804$. Nilai koefisien determinasi yang tinggi antara nilai LAI dengan nilai reflektan panjang gelombang near infrared menunjukkan bahwa nilai reflektan panjang gelombang near infrared merepresentasikan kondisi daun tanaman padi.

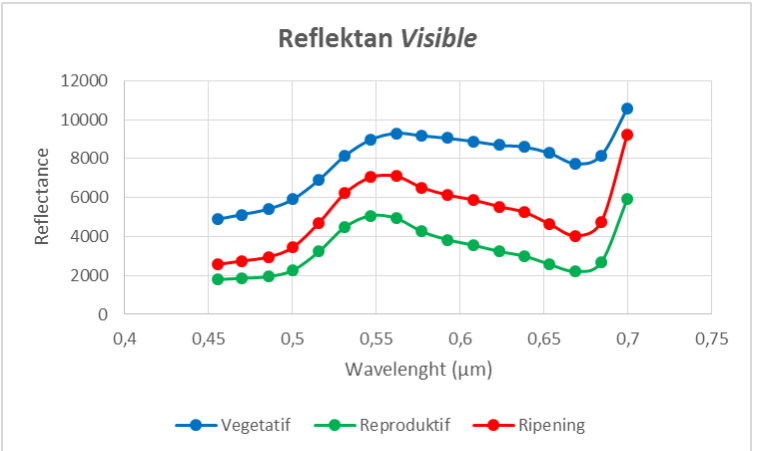

Gambar 6. Reflektan spektral setiap fase tumbuh padi panjang gelombang visible Fase Vegetatif

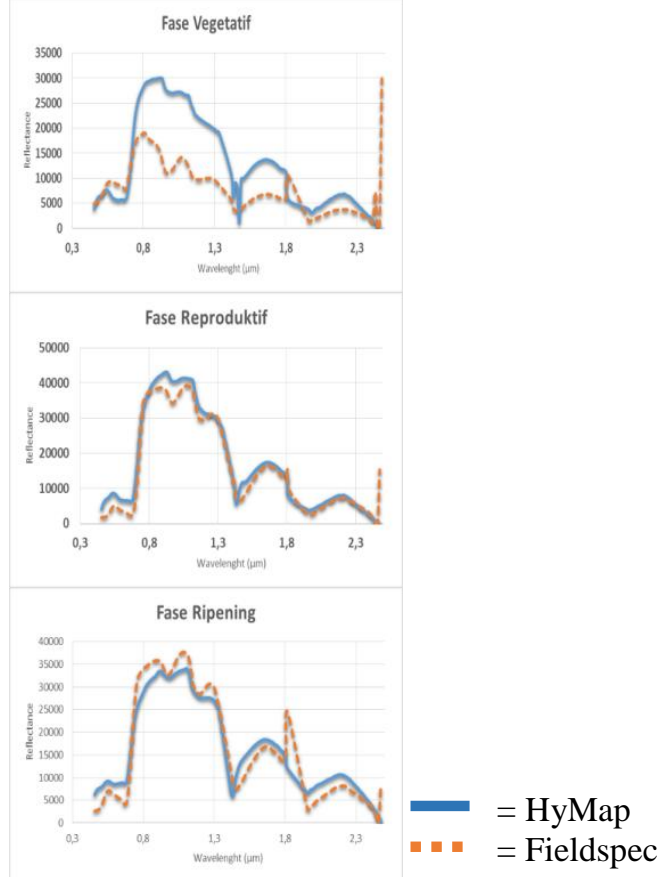

Gambar 7. Reflektan spektral setiap fase pertumbuhan padi pada panjang gelombang $(0,45-$ 2,5 $\mu \mathrm{m}$ )

Dari gambar 4 dapat dijelaskan kondisi setiap fase pertumbuhan padi, pada fase vegetatif ditunjukkan dengan profil reflektan yang memiliki nilai cenderung tinggi pada panjang gelombang visible. Sedangkan pada panjang gelombang near infrared memiliki nilai reflektan yang rendah. Hal ini dapat dijelaskan bahwa pada fase vegetatif ditunjukkan dengan profil reflektan yang memiliki nilai rendah pada spektrum gelombang near infrared dan relatif tinggi pada spektrum gelombang visible dikarenakan pada fase vegetatif masih tergolong muda dan kecil, maka hanya sebagian kecil energi pada panjang gelombang biru dan merah yang diserap untuk proses fotosintesis [3].

Profil reflektan pada fase reproduktif menunjukkan nilai reflektan pada panjang gelombang visible yang lebih rendah dibandingkan fase vegetatif. Hal ini dikarenakan pada panjang gelombang biru dan merah energi lebih banyak diserap untuk melakukan proses fotosintesis [3]. Sedangkan pada panjang gelombang near infrared memiliki nilai reflektan yang tinggi, maka energi lebih banyak yang dipantulkan karena struktur daun pada fase reproduktif menutup rapat sehingga tidak ada reflektan pantulan dari tanah atau air [5].

Pada fase ripening, nilai reflektan panjang gelombang visible khususnya panjang gelombang merah cenderung naik sedangkan pada panjang gelombang near infrared nilai reflektan masih cenderung tinggi. Hal ini dapat dijelaskan untuk fase ripening kondisi vegetasi terutama daun sudah mengalami pelayuan (senescence) yang mengindikasikan bahwa kandungan klorofil sudah mulai menurun, sehingga pada tahap ini warna daun sudah mulai menguning yang berarti tingkat fotosintesis vegetasi juga sudah mulai menurun [3].

Spectral Reference Stage Pertumbuhan Padi Pembagian kelas pertumbuhan padi berdasarkan standar tahap pertumbuhan padi yang dibuat oleh International Rice Research Institute (IRRI), pada fase vegetatif (Seedling, Tillering, Stem Elongation). Penentuan stage pertumbuhan padi dilakukan dengan menggabungkan informasi lapangan nilai LAI dan umur padi dengan karakteristik spektral dan bentuk spektral untuk setiap stage pada quadrat area padi yang mewakili setiap fase tumbuh. 
Tabel 2. Nilai LAI, plant height rata-rata dan umur setiap stage pertumbuhan padi

\begin{tabular}{|l|l|l|l|}
\hline Stage Tumbuh & LAl & $\begin{array}{l}\text { Plant Height } \\
(\mathrm{cm})\end{array}$ & $\begin{array}{l}\text { Umur } \\
\text { (hari) }\end{array}$ \\
\hline Seedling & 0,132 & 29,8 & $0-30$ \\
\hline Tillering & 0,390 & 43,5 & $31-45$ \\
\hline $\begin{array}{l}\text { Stem } \\
\text { Elongation }\end{array}$ & 1,392 & 56,2 & $46-55$ \\
\hline $\begin{array}{l}\text { Penicle } \\
\text { Initation To } \\
\text { Booting }\end{array}$ & 2,014 & 76,6 & $56-72$ \\
\hline Heading & 3,704 & 95,2 & $73-81$ \\
\hline Flowering & 5,026 & 115 & $82-90$ \\
\hline Milk Grain & 2,864 & 94,8 & $91-100$ \\
\hline Dough Grain & 3,940 & 112,8 & $\begin{array}{l}101 \\
111\end{array}$ \\
\hline Mature Grain & 4,898 & 123,8 & $\begin{array}{l}111 \\
120\end{array}$ \\
\hline
\end{tabular}

Profil reflektan spektral setiap stage pada masing-masing fase pertumbuhan tanaman padi yang dijadikan sepktral referensi (Spectral Reference) digambarkan pada gambar berikut :

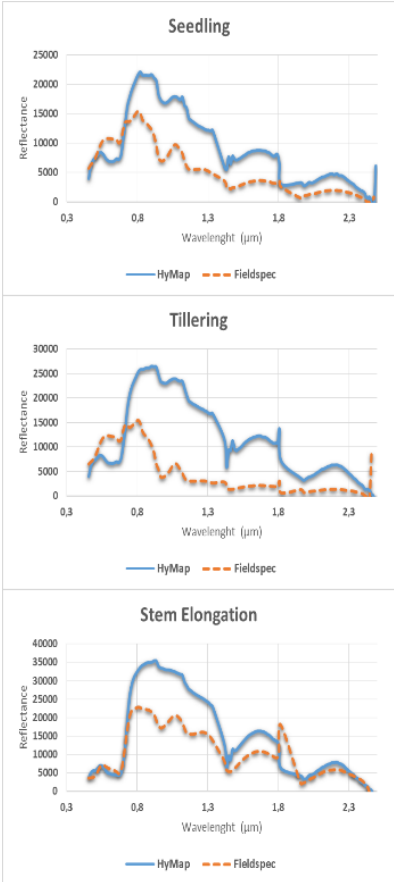

Gambar 8. Profil reflektan spektral stage fase vegetatif padi (Seedling, Tillering, Stem Elongation)

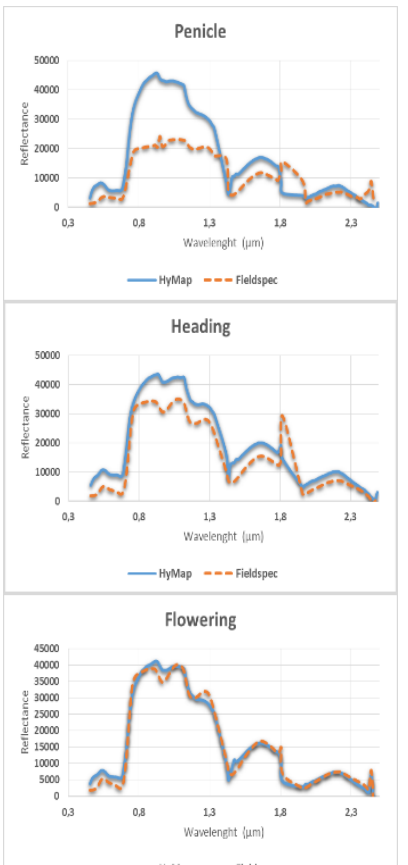

Gambar 8. Profil reflektan spektral stage fase reproduktif padi (Penicle Initation to booting, Heading, Flowering)

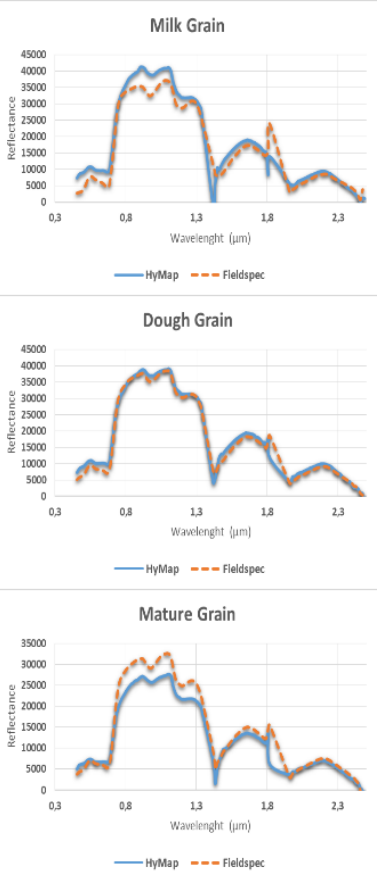

Gambar 9. Profil reflektan spektral stage fase ripening padi (Milk Grain, Dough Grain, Mature Grain)

Klasifikasi Fase Pertumbuhan Padi Citra HyMap Klasifikasi pemetaan fase pertumbuhan padi yang dibagi menjadi 9 kelas berdasarkan standar tahap pertumbuhan padi yang dibuat oleh International Rice Research Institute (IRRI). Dari setiap fase 
tumbuh dibagi menjadi 3 stage yaitu vegetatif (Seedling, Tillering, Stem Elongation), reproduktif (Penicle Initation to booting, Heading, Flowering), ripening (Milk Grain, Dough Grain, Mature Grain). Klasifikasi citra HyMap berdasarkan spectral reference yang telah disusun dengan metode SAM dan SVM kemudian dilakukan analisa hasil klasifikasi dengan menguji hasil ketelitian klasifikasi pemetaan fase pertumbuhan padi.

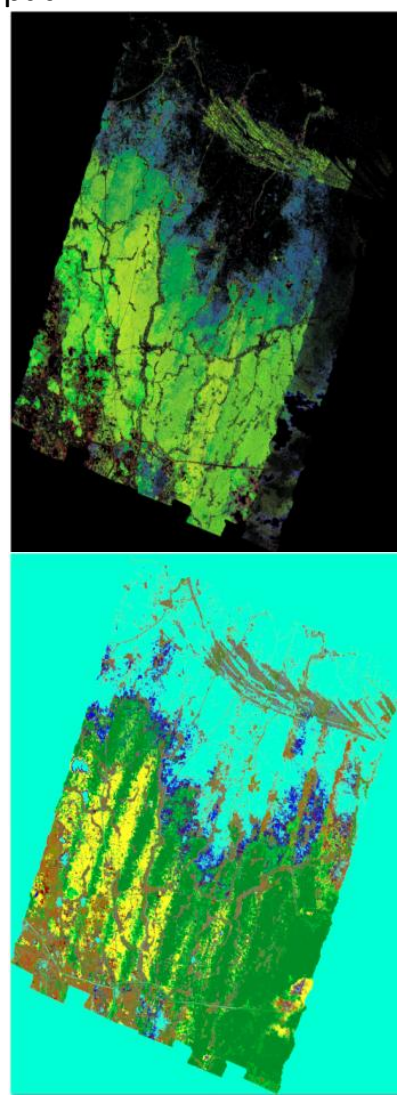

(b)

Gambar 4.14 Hasil klasifikasi SAM (a) dan SVM (b)

Dari hasil klasifikasi stage pertumbuhan padi dengan metode SAM dan SVM yang telah dilakukan, didapatkan ketelitian dengan metode confusion matriks adalah sebagai berikut :

Tabel 3. Ketelitian hasil klasifikasi SAM dan SVM

\begin{tabular}{|l|l|l|l|}
\hline \multirow{2}{*}{ No } & \multirow{2}{*}{ Stage Tumbuh } & \multicolumn{2}{|l|}{ Ketelitian (\%) } \\
\cline { 3 - 4 } & & SAM & SVM \\
\hline 1 & Seedling & 42,857 & 37,5 \\
\hline 2 & Tillering & 38,095 & 33,333 \\
\hline 3 & Stem Elongation & 66,667 & 60 \\
\hline 4 & $\begin{array}{l}\text { Penicle Initation to } \\
\text { booting }\end{array}$ & 63,636 & 24 \\
\hline 5 & Heading & 38,462 & 7,692 \\
\hline
\end{tabular}

\begin{tabular}{|l|l|l|l|}
\hline 6 & Flowering & 69,231 & 42,857 \\
\hline 7 & Milk Grain & 33,333 & 66,667 \\
\hline 8 & Dough Grain & 25 & 66,667 \\
\hline 9 & Mature Grain & 75 & 44,444 \\
\hline & Total & 82,609 & 54,348 \\
\hline
\end{tabular}

Dari tabel 4.8 menunjukkan bahwa ketelitian hasil klasifikasi SAM sebesar 82,609 \% lebih teliti dibandingkan hasil klasifikasi SVM yang memilki ketelitian 54,348 \% maka hasil klasifikasi dengan metode SAM memenuhi syarat sebagai pemetaan persebaran pertumbuhan tanaman padi karena ketelitian hasil klasifikasi $>80 \%$.

Luasan area pada masing-masing stage dari hasil pemetaan persebaran pertumbuhan tanaman padi ditunjukkan pada tabel 4.9 sebagai berikut

Tabel 4. Luas area setiap stage pertumbuhan padi

\begin{tabular}{|l|l|l|}
\hline No & Stage Tumbuh & Luas $\left(\mathrm{km}^{2}\right)$ \\
\hline 1 & Seedling & 12,568 \\
\hline 2 & Tillering & 20,344 \\
\hline 3 & Stem Elongation & 41,051 \\
\hline 4 & $\begin{array}{l}\text { Penicle Initation to } \\
\text { booting }\end{array}$ & 29,617 \\
\hline 5 & Heading & 30,004 \\
\hline 6 & Flowering & 74,070 \\
\hline 7 & Milk Grain & 14,599 \\
\hline 8 & Dough Grain & 13,337 \\
\hline 9 & Mature Grain & 15,213 \\
\hline 10 & Unclassified & 519,063 \\
\hline & Total & 769,865 \\
\hline
\end{tabular}

Klasifikasi SAM memiliki hasil akurasi lebih baik dikarenakan untuk clustering dan klasifikasi citra menggunakan bentuk pola spektral sehingga penganalisa mampu menggabungkan informasi lapangan dengan karakteristik spektral dan bentuk spektral untuk setiap jenis objek yang berbeda [6]. Sedangkan dalam penggunaan metode klasifikasi SVM akan mendapatkan hasil yang akurat dan signifikan pada region kelas yang homogen [7]. Sehingga dapat disimpulkan bahwa metode klasifikasi SVM kurang cocok untuk mengklasifikasikan fase pertumbuhan padi yang bersifat heterogen dan spesifik.

\section{KESIMPULAN DAN SARAN}

Dari hasil klasifikasi fase pertumbuhan tanaman padi yang dikelaskan berdasarkan analisis nilai 
reflektan spektral citra HyMap, digunakan metode klasifikasi SAM dan SVM. Hasil uji ketelitian klasifikasi SAM sebesar 82,609\% sedangkan hasil klasifikasi SVM sebesar 54,348 \%. Dari Hasil uji ketelitian tersebut dapat disimpulkan bahwa klasifikasi dengan metode SVM tidak memenuhi persyaratan $>80 \%$ pada uji ketelitian klasifikasi, sedangkan klasifikasi dengan metode SAM memenuhi persyaratan $>80 \%$ pada uji ketelitian klasifikasi. Sehingga metode klasifikasi berbasis analisis nilai spektral dalam memetakan fase pertumbuhan padi pada citra HyMap lebih optimal menggunakan metode SAM daripada menggunakan metode SVM.

Pemetaan fase pertumbuhan tanaman padi pada area studi Kabupaten Karawang memperoleh hasil luasan area pemetaan pada setiap kelas (stage) adalah sebagai berikut: Seedling $=12,568$ $\mathrm{km}^{2}$, Tillering $=20,344 \mathrm{~km}^{2}$, Stem Elongation $=$ $41,051 \mathrm{~km}^{2}$, Penicle Initation to booting $=29,617$ $\mathrm{km}^{2}$, Heading $=30,004 \mathrm{~km}^{2}$, Flowering $=74,070$ $\mathrm{km}^{2}$, Milk Grain $=14,599 \mathrm{~km}^{2}$, Dough Grain $=$ $13,337 \mathrm{~km}^{2}$, Mature Grain $=15,213 \mathrm{~km}^{2}$.

\section{DAFTAR PUSTAKA}

Wibowo, Agus. 2011. “Pengembangan Metode Estimasi Kandungan Air Kanopi Daun (Canopy Water Content) Tanaman Padi dengan Data Hyperspektral". Institut Teknologi Sepuluh Nopember. Surabaya.

Wang et al. 2008. "Optimal wave kanal identification for estimation of leaf area index of paddy rice" Journal of Zheijang UniversityScience B. 9 (12) 953-963.

Darmawan, Arief. 2012. “Pembangunan Model Hyperspectral Untuk Estimasi Produktivitas Vegetasi Padi Berdasarkan Metode Derivatif Regresi Linear". Institut Teknologi Sepuluh Nopember. Surabaya.

Mather, Paul M. 2004. "Computer Processing of Remotely-Sensed( Third Edition)". John Wiley \& Sons Ltd : Chichester.

Ratnasari, Dian. 2010. "Penggunaan Data Hyperspectral Fieldspec dan Airborne HyMap ntuk Perhitungan Canopy Water Content (CWC) Tanaman Padi Di Kabupaten Indramayu, Propinsi Jawa Barat". Institut Teknologi Sepuluh Nopember. Surabaya.
Y. Sohn dan N.S Rebello. 2002. "Supervised and Unsupervised Spectral Angle Classifiers". Photogrammetric Engineering \& Remote Sensing Vol. 68, No. 12, December 2002, pp. 1271-1280.

Y. Tarabalka. 2010. "Classification Of Hyperspectral Data Using Support Vector Machines And Adaptive Neighborhoods". GIPSA-Lab, Grenoble Institute of Technology, Domaine Universitaire - BP 46, 38402, Saint-Martin-d'Hères, France. 